\section{Theoretical \& Applied Science}

p-ISSN: 2308-4944 (print) $\quad$ e-ISSN: 2409-0085 (online)

$\begin{array}{lll}\text { Year: } 2016 \quad \text { Issue: } 7 & \text { Volume: } 39\end{array}$

Published: $30.07 .2016 \quad \underline{\text { http://T-Science.org }}$

\section{Denis Chemezov}

Master of Engineering and Technology, Corresponding Member of International Academy of Theoretical and Applied Sciences, Lecturer of Vladimir Industrial College, Russian Federation chemezov-da@yandex.ru

SECTION 7. Mechanics and machine construction.

\title{
THE WEAR RESISTANCE OF THE REPLACEABLE MULTIFACETED PLATE DURING THE TURNING OF STAINLESS STEEL AT VARIOUS CUTTING CONDITIONS
}

Abstract: The article is presented a comparison of the wear amount of the surfaces and the cutting edges of the replaceable multifaceted plate after longitudinal turning of workpieces made of difficult to machine steel on a lathe with numerical control. The mechanical processing was performed while changing the feed rate of the cutting tool and rotational speed of the workpiece.

Key words: turning, wear, RMP, cutting edge, rear surface.

Language: Russian

Citation: Chemezov DA (2016) THE WEAR RESISTANCE OF THE REPLACEABLE MULTIFACETED PLATE DURING THE TURNING OF STAINLESS STEEL AT VARIOUS CUTTING CONDITIONS. ISJ Theoretical \& Applied Science, 07 (39): 57-64.

Soi: $\underline{\text { http://s-o-i.org/1.1/TAS-07-39-10 Doi: crossef http://dx.doi.org/10.15863/TAS.2016.07.39.10 }}$

\section{ИЗНОСОСТОЙКОСТЬ СМЕННОЙ МНОГОГРАННОЙ ПЛАСТИНЫ ПРИ ТОЧЕНИИ НЕРЖАВЕЮЩЕЙ СТАЛИ НА РАЗЛИЧНЫХ РЕЖИМАХ РЕЗАНИЯ}

Аннотация: В статье представлено сравнение величины износа плоскостей и режущих кромок сменной многогранной пластины после продольного точения заготовок, изготовленных из труднообрабатываемой стали, на токарном станке с числовым программным управлением. Механическая обработка выполнялась при изменении скорости подачи режущего инструмента и частоты вращения заготовки.

Ключевые слова: точение, износ, СМП, режущая кромка, задняя поверхность.

В условиях автоматизированной обработки деталей сокращение времени переналадки режущего инструмента обеспечивается при применении сменных многогранных пластин (СМП). Затупившаяся режущая часть СМП не затачивается, а меняется на новую путем поворота пластины в резцовой державке.

Производительность механической обработки с соблюдением технических требований к изготовлению деталей машин на технологическом оборудовании зависит от периода стойкости режущего инструмента [1]. Под стойкостью понимают время работоспособности режущего инструмента до одного из критериев износа [2].

Во время резания происходит процесс изнашивания плоскостей инструмента [3]. При этом изменяются размеры и геометрия режущего инструмента, приводящие к погрешности размеров и ухудшению качества поверхностного слоя детали. В зависимости от режимов резания, обрабатываемого материала, характера обработки и других факторов различают следующие виды износа СМП:

1. Образование нароста (наплавление обрабатываемого материала) на режущей кромке, приводящее к еe выкрашиванию и, следовательно, к снижению качества обработанной поверхности детали.

2. Износ по задней поверхности возникает в результате контакта пластины с обрабатываемым материалом в процессе резания.

3. Лунка на передней поверхности. Размеры лунки зависят от обрабатываемого материала. Более широкая и мелкая лунка образуется при точении мягких материалов, узкая и глубокая при обработке твердых материалов. 
4. Окислительная трещина на вспомогательной режущей кромке в совокупности с лункой на передней поверхности пластины многократно повышают шероховатость обработанной поверхности детали.

5. Пластическая деформация вершины происходит от перегрузки режущей кромки в результате высоких температур в зоне резания.

6. Проточина на главной режущей кромке образуется при обработке коррозионностойких аустенитных сталей. Наблюдается упрочнение поверхностных слоев материала заготовки.

7. Выкрашивание режущей грани пластины встречается в сочетании с другими видами износа.

8. Разрушение режущей кромки (вне зоны резания) происходит при неудовлетворительном процессе стружкодробления.

9. Термотрещины являются следствием динамической тепловой нагрузки на режущую кромку в процессе прерывистого резания.

10. Усталостные трещины возникают за режущей кромкой в результате динамической нагрузки.

11. Разрушение режущей кромки или вершины инструмента при малой жесткости системы «станок - инструмент - заготовка» и не правильно подобранных условий резания.

При точении наблюдается наибольшая степень износа режущего инструмента, чем при других видах лезвийной обработки. В качестве основного критерия износа СМП чаще всего принимается износ по задней поверхности.

Нержавеющие, жаростойкие, жаропрочные и другие подобные стали являются труднообрабатываемыми. Неправильно подобранные режимы резания и материал СМП могут привести к увеличению интенсивности процесса изнашивания при обработке.

Определение величины абразивного износа поверхностей СМП при продольном точении труднообрабатываемой стали на различных режимах резания позволит сделать прогноз работоспособности режущего инструмента.

Точение выполнялось на токарном станке с числовым программным управлением (ЧПУ) модели HAAS TL-1 (серия Toolroom, США) [4]. Высокая точность станка с ЧПУ позволяет минимизировать погрешности обработки (диаметральные и линейные размеры детали), связанные с линейным позиционированием исполнительного органа (суппорта).

Обрабатываемая деталь «Палец» представляла собой ступенчатый валик с коническими переходами между ступенями. Схема установки заготовки и точения детали с указанием межоперационных припусков на обработку представлена на рис. 1. Пруток закреплялся в токарном трехкулачковом патроне и обтачивался по наружному диаметру. Реальная схема обработки детали: закрепление левого конца прутка, а обрабатываемая часть будет представлять собой консоль.

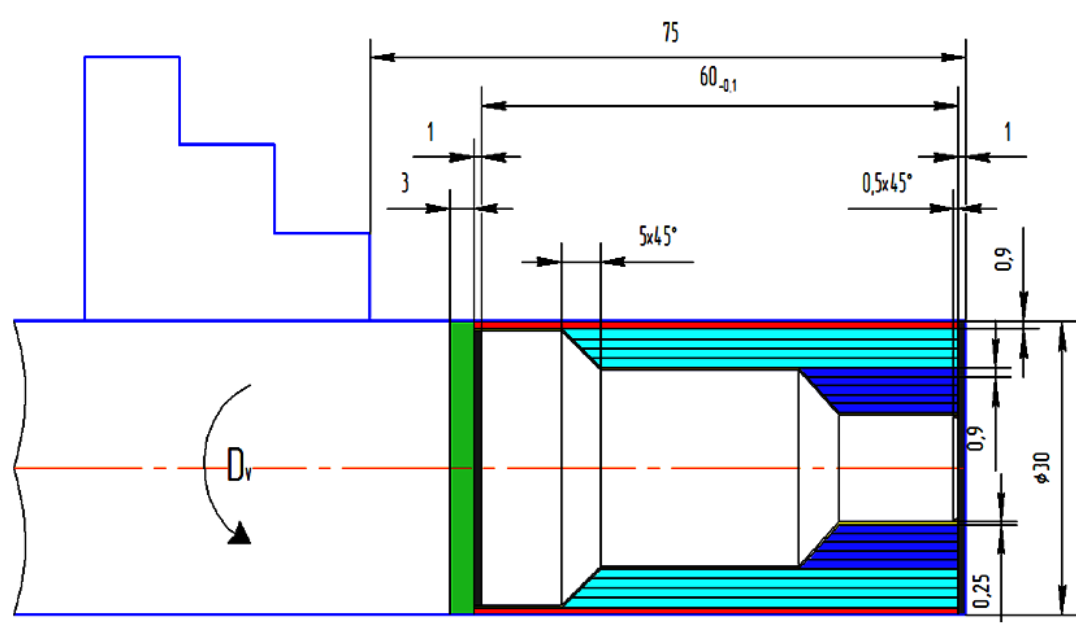

Точение продольное, черновой проход (×1)

Точение продольное, черновой проход (×4)

Точение продольное, черновой проход (×5)

Точение комбинированное, чистовой проход (×1)

Подрезка торца, чистовой проход $(\times 2)$

Точение фаски (×1)

Отрезание $(\times 1)$

Рисунок 1 - Схема обработки детали «Палец». 
Общая длина обработки (рабочий ход режущего инструмента) рассчитывалась при суммировании длин обработки отдельных поверхностей детали: подрезка торца в размер 74 мм (1 проход, $t$ (глубина резания) $=1$ мм, расчетная длина обработки $l=15$ мм), точение $\varnothing 28.2$ мм на длину 65 мм ( 1 проход, $t=0.9$ мм, расчетная длина обработки $l=65$ мм), точение Ø20.2 мм на длину 45 мм (4 прохода, $t=0.9$ мм, расчетная длина обработки $l=180 \mathrm{Mм})$, точение Ø11.2 мм на длину 15 мм (5 проходов, $t=0.9$ мм, расчетная длина обработки $l=75 \mathrm{Mм})$, окончательное точение контура детали, выдерживая размеры Ø11 -0.08 мм, Ø20-0.1 мм, Ø28. 0.15 Мм, 15-0.1 Мм, 30-0.1 мм и 60-0.15 мм (1 проход, $t$ $=0.25 \mathrm{Mм}$, расчетная длина обработки $l=65 \mathrm{Mм})$, отрезка детали от прутка на длину 61 мм (1 проход, $t=3$ мм, расчетная длина обработки $l=$ 15 мм), подрезка торца в размер 60-0.1 мм (1 проход, $t=1$ мм, расчетная длина обработки $l=$ 15 мм). Общая длина обработки (без операции отрезания) составила 415 мм.

Механическая обработка велась на двух режимах резания: 1 режим - скорость подачи режущего инструмента $s=0.15$ мм/об, частота вращения заготовки $n=500$ мин $^{-1}, 2$ режим скорость подачи режущего инструмента $s=0.1$ мм/об, частота вращения заготовки $n=600$ мин $^{-1}$. Расход смазочно-охлаждающей жидкости (СОЖ) при обработке деталей на двух режимах резания был одинаковым и составлял $1.4 \times 10^{-3} \mathrm{M}^{3} / \mathrm{c}$. На каждом режиме обрабатывались по две детали.

Обрабатываемый материал - нержавеющая титаносодержащая сталь аустенитного класса 12Х18Н10T [5]. Содержание в стали железа составляет $67.925 \%$, хрома - $18 \%$, никеля - 10 $\%$, марганца $-2 \%$, кремния $-0.8 \%$, титана -0.8 $\%$, меди - $0.3 \%$, углерода - $0.12 \%$, фосфора $0.035 \%$, серы - $0.02 \%$. Предел кратковременной прочности $S_{6}$ стали составляет $510 \mathrm{MПа,} \mathrm{предел}$ пропорциональности $S_{T} \quad-196$ МПа, относительное удлинение при разрыве $\delta-40 \%$, относительное сужение $\psi-55 \%$.

Обработка производилась пластинами квадратной формы из твердого сплава марки Т15К6 (карбид вольфрама - 79 \%, карбид титана - $15 \%$, кобальт - 6 \%) [6]. Форма и размеры СМП представлены на чертеже (рис. 2).

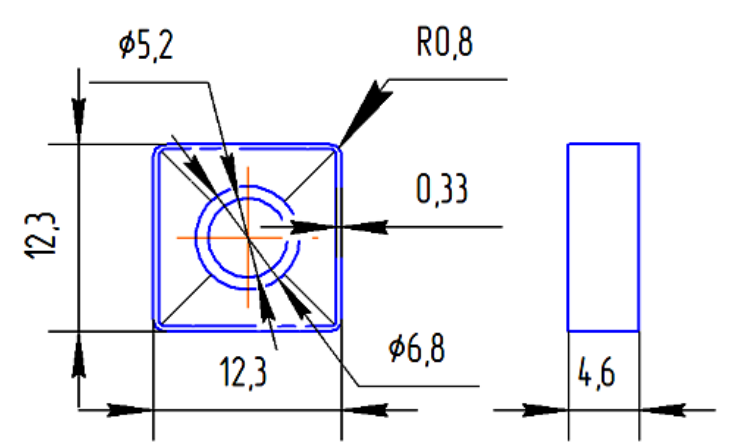

Рисунок 2 - Чертеж СМП квадратной формы.

СМП имела следующую геометрию: главный угол в плане $\varphi=45^{\circ}$, вспомогательный угол в плане $\varphi_{1}=45^{\circ}$, задний угол $\alpha=6^{\circ}$, передний угол $\gamma=12^{\circ}$. Твердый сплав Т15К6 обладает высоким пределом прочности при

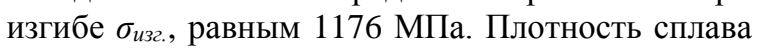
составляет $11.5 \mathrm{\Gamma} / \mathrm{cm}^{3}$. Измерение твердости сплава Т15К6 и определение состояния поверхностей СМП до обработки выполнялось на многофункциональной установке Микро скретчтестер фирмы CSM Instruments (Швейцария) [7, $8]$.

Микро скретч-тестер позволяет определять микротвердость, модуль упругости (измерительное индентирование), адгезионную прочность и стойкость к царапанию различных материалов. Установка управляется при помощи персонального компьютера и подключенных к нему двух мониторов. Возможны следующие методы анализа: оптический анализ (микроскопия), анализ акустической эмиссии, анализ силы трения и анализ глубины погружения индентора. Статистическая обработка результатов измерения выполняется по среднему значению, стандартному отклонению, минимуму, максимуму, медиане и числу точек измерений на образец. Предусмотрен экспорт экспериментальных данных и статистической обработки результатов измерения в текстовом виде в Excel.

Общий вид установки Микро скретч-тестер и ориентация режущей пластины при измерении представлены на рис. 3. На фотографиях (а и б) обозначены: 1 - неподвижная опора для монтажа узлов установки, 2 - измерительная головка, 3 модуль с USB камерой, 4 - подвижный столик в $\mathrm{Z}$ перемещении, 5 - антивибрационный стол, 6 компрессор, 7 - измерительный модуль, 8 и 9 набор объективов $(5 \times, 20 \times, 50 \times)$ с увеличением соответственно в 200, 800 и 2000 раз, 10 - 


\begin{tabular}{|c|c|c|c|c|c|c|}
\hline Impact Factor: & $\begin{array}{l}\text { ISRA (India) } \\
\text { ISI (Dubai, UAE } \\
\text { GIF (Australia) } \\
\text { JIF }\end{array}$ & $\begin{array}{r}=1.344 \\
=0.829 \\
=0.564 \\
=1.500\end{array}$ & $\begin{array}{l}\text { SIS (USA) } \\
\text { PИНЦ (Russia } \\
\text { ESJI (KZ) } \\
\text { SJIF (Moroccc }\end{array}$ & $\begin{aligned}= & 0.912 \\
= & 0.234 \\
= & \mathbf{1 . 0 4 2} \\
= & \mathbf{2 . 0 3 1}\end{aligned}$ & $\begin{array}{l}\text { ICV (Poland) } \\
\text { PIF (India) } \\
\text { IBI (India) }\end{array}$ & $\begin{array}{l}=6.630 \\
=1.940 \\
=4.260\end{array}$ \\
\hline
\end{tabular}

виброопора, 11 - приспособление для закрепления образцов, 12 - СМП, 13 переключатель на 2 режима работы: вдавливание (твердость, модуль упругости, упругое восстановление) и царапание (твердость по Моосу, адгезионная/когезионная прочность, стойкость к царапанию).

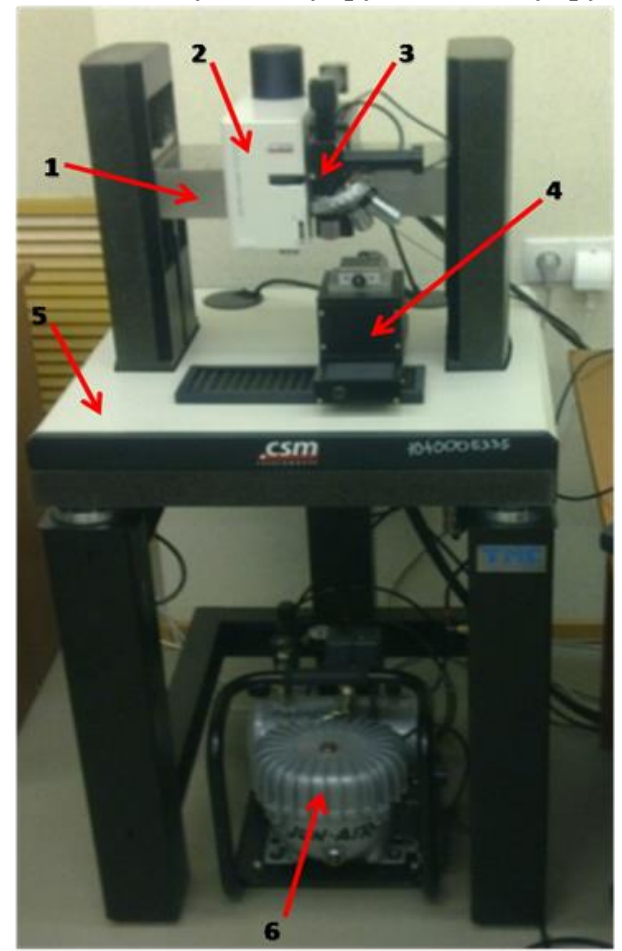

a)

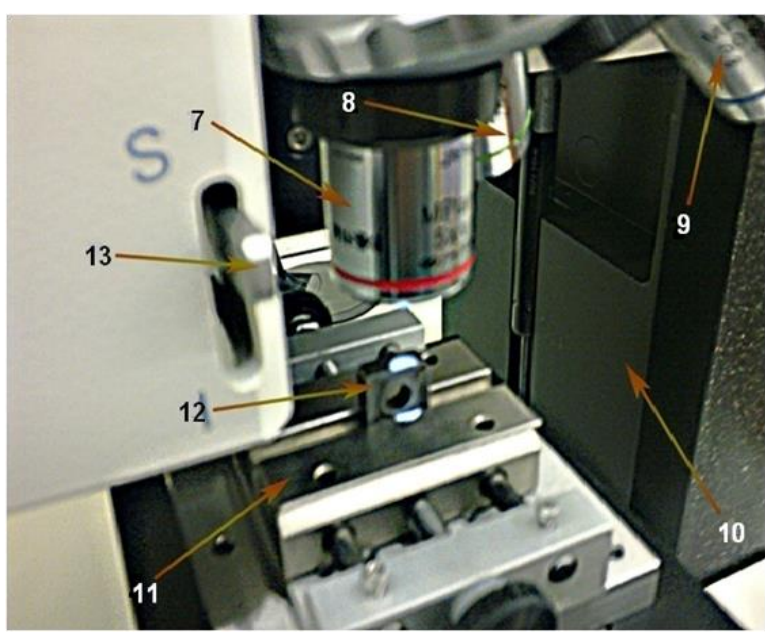

б)

Рисунок 3 - Установка Микро скретч-тестер для измерения твердости и износа СМП: а - общий вид, б - ориентация режущей пластины.

Твердость сплава Т15К6 определялась путем вдавливания алмазного индентора в поверхность СМП. Максимальная линейная нагрузка, приложенная на индентор, принималась величиной $15 \mathrm{H}$, скорость нагрузки/разгрузки 30 Н/мин, выдержка времени - 5 с.

Измерение проводилось по следующим методам (обработка результатов по среднему значению двух измерений):

1. Метод Оливера-Фарра: твердость при вдавливании - 16.734 ГПа, модуль индентирования - 235.135 ГПа, модуль упругости - 210.615 ГПа, твердость по Виккерсу - 1579.47, ползучесть при индентировании - $0.795 \%$, релаксация напряжения в материале при индентировании - $-0.105 \%$, глубина проникновения индентора -7.736 мкм.

2. Тангенциальный (касательный) метод: твердость при вдавливании - 20.473 ГПа, модуль индентирования - 242.455 ГПа, твердость по Виккерсу - 1932.45.

3. Метод Мартенса: твердость по Мартенсу -9.554 ГПа.

Схемы установки СМП в зажимном приспособлении установки Микро скретч-тестер и обозначение мест для увеличения представлены на рис. 4.

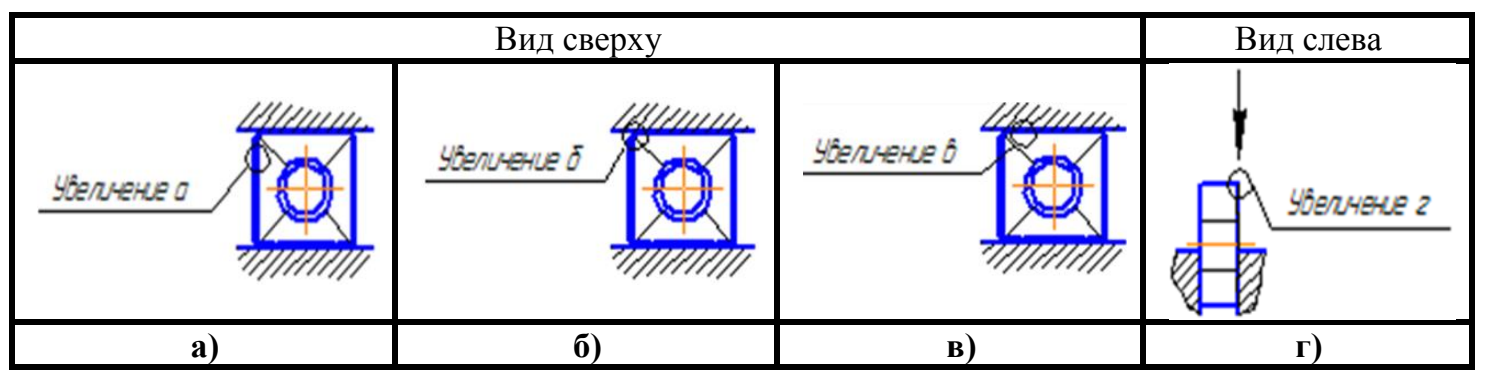

Рисунок 4 - Схемы установки СМП в приспособлении установки и обозначение мест для увеличения: a - главной режущей кромки, б - радиусной режущей кромки, в - вспомогательной режущей кромки, г - задней поверхности.

ISPC Results and Perspectives,

Harrisburg, USA 
Увеличенные в 200 раз изображения состояния поверхностей СМП до точения представлены на рис. 5.

Общее состояние режущих кромок и поверхностей СМП удовлетворительное. Наблюдается равномерная структура сплава. Неровности поверхностей минимальны. На пересечении граней пластины ленточка

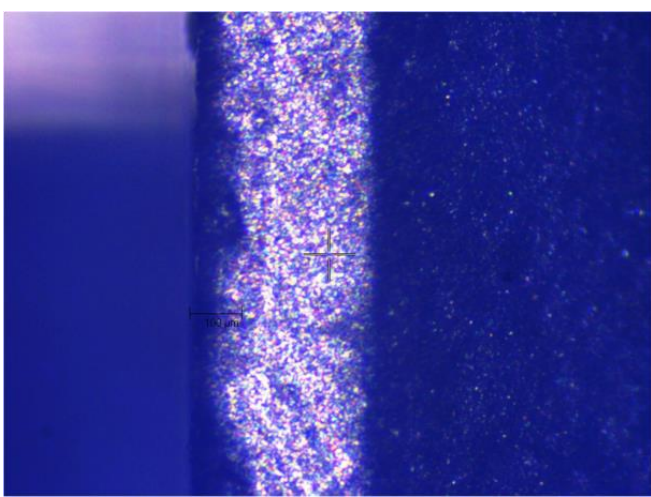

a)

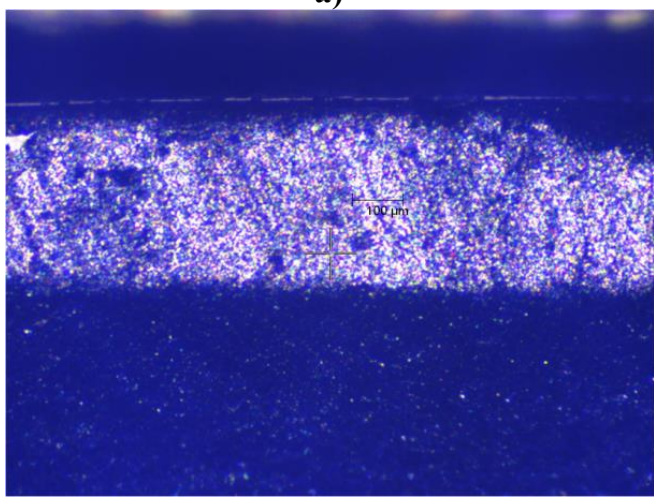

B) утолщается. Интенсивность абсолютного износа по передней поверхности определялась по состоянию ленточки твердосплавной пластины. Для осуществления эксперимента в производственных условиях были отобраны две твердосплавные пластины с соответствующим состоянием поверхностей и режущих кромок.

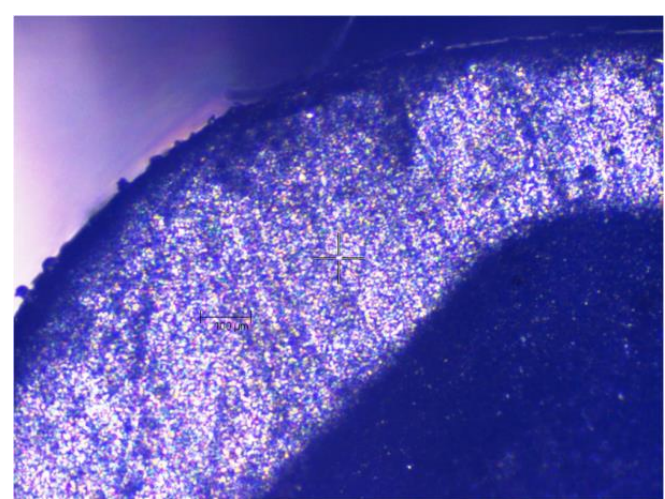

б)

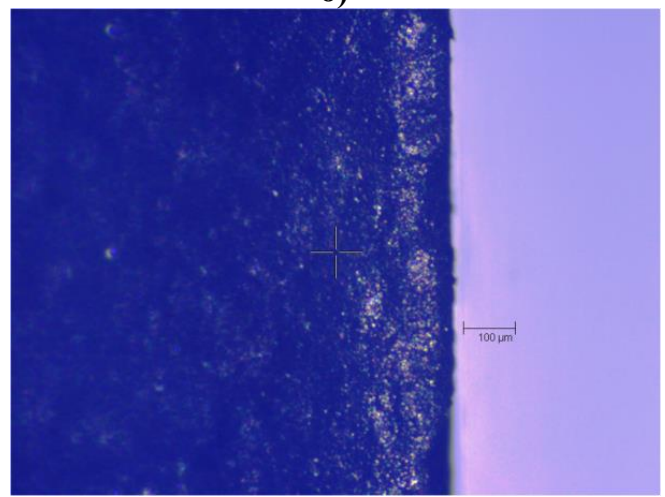

г)

Рисунок 5 - Состояние поверхностей СМП до обработки: а - главная режущая кромка, б - радиусная режущая кромка, в - вспомогательная режущая кромка, г- задняя поверхность. Увеличение в 200 pa3.

Величину износа поверхностей СМП определяли после обработки двух деталей на каждом режиме резания. Увеличенные в 200 раз изображения состояния поверхностей СМП после обтачивания нержавеющей стали на различных режимах резания представлены на рис. 6 и 7 соответственно.

На первом и втором режимах резания абсолютный износ по передней поверхности СМП представлен истиранием части ленточки.

\section{1 режим резания}

На главной режущей кромке пластины величина износа достигает 0.3 мм (300 мкм). В области радиусной вершины СМП износ происходит по ленточке и поверхности, по которой сходит стружка. Вспомогательная режущая кромка пластины менее подвергается износу, так как она практически не контактирует c обрабатываемой поверхностью заготовки.
Износ величиной 0.5 мм (500 мкм) наблюдается по задней поверхности СМП. Расчетное время резания материала (обработка двух деталей) на данном режиме составило 11.04 мин.

\section{2 режим резания}

Износ главной режущей кромки имеет меньшую интенсивность, чем при первом режиме резания. Однако на радиусной вершине СМП отмечена лунка износа (на ленточке) шириной около 0.4 мм (400 мкм). Аналогичные лунки износа, но меньших размеров, наблюдаются и на вспомогательной режущей кромке пластины. Износ по задней поверхности СМП составляет 0.9 мм (900 мкм). Частицы обрабатываемого материала спекаются, образуя нарост. Расчетное время резания материала (обработка двух деталей) на данном режиме составило 13.82 мин. 


\begin{tabular}{l|lrl|l|ll} 
& ISRA (India) & $=\mathbf{1 . 3 4 4}$ & SIS (USA) & $=\mathbf{0 . 9 1 2}$ & ICV (Poland) & $=\mathbf{6 . 6 3 0}$ \\
Impact Factor: & ISI (Dubai, UAE) $=\mathbf{0 . 8 2 9}$ & PUHU (Russia) $=\mathbf{0 . 2 3 4}$ & PIF (India) & $=\mathbf{1 . 9 4 0}$ \\
& GIF (Australia) & $\mathbf{0 . 5 6 4}$ & ESJI (KZ) & $=\mathbf{1 . 0 4 2}$ & IBI (India) & $\mathbf{4 . 2 6 0}$
\end{tabular}

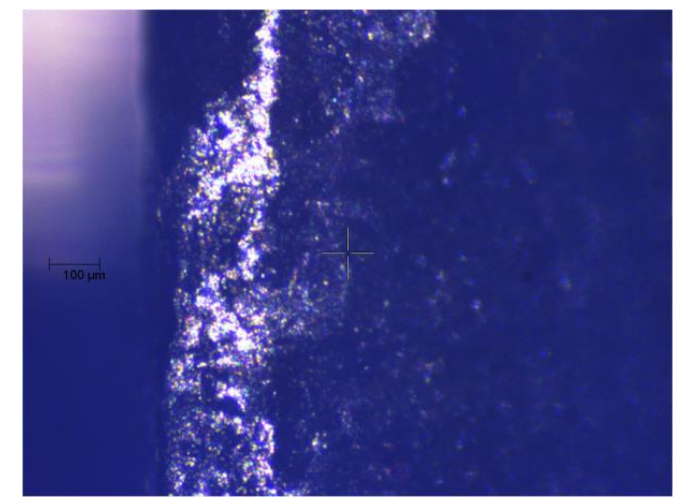

a)

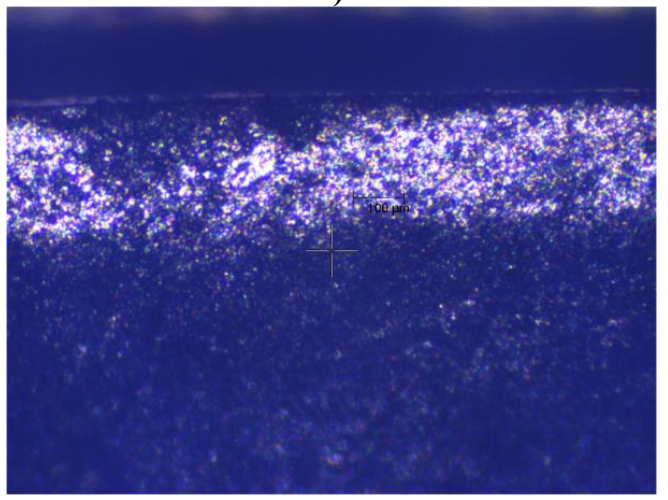

B)

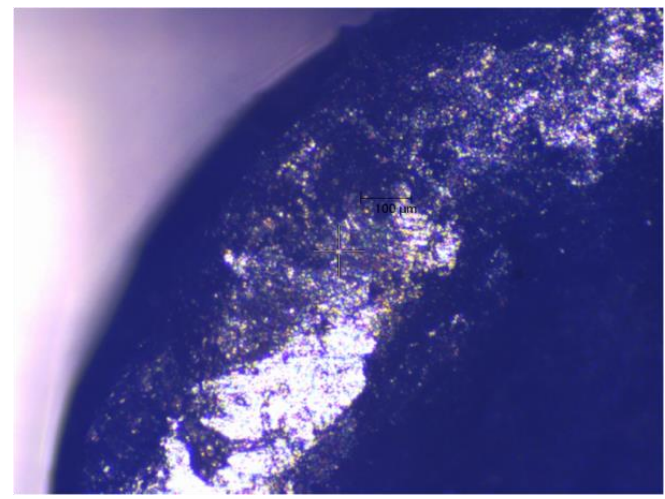

б)

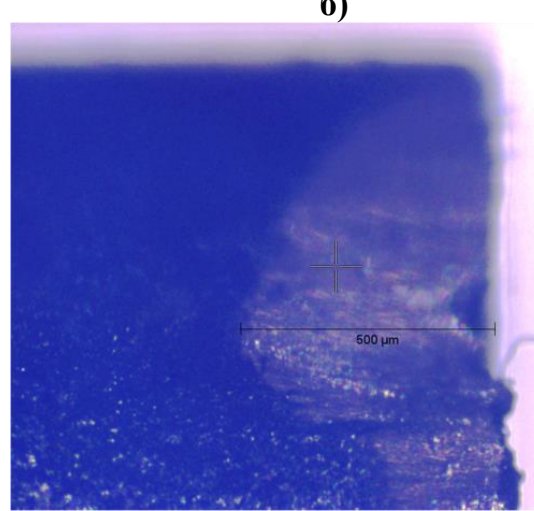

г)

Рисунок 6 - Износ поверхностей СМП после обработки на 1 режиме резания: а - главная режущая кромка, $\boldsymbol{\sigma}$ - радиусная режущая кромка, в - вспомогательная режущая кромка, г - задняя поверхность. Увеличение в 200 раз.

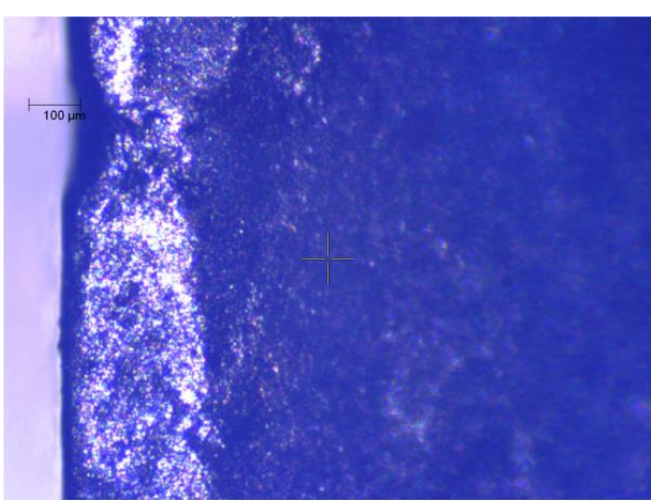

a)

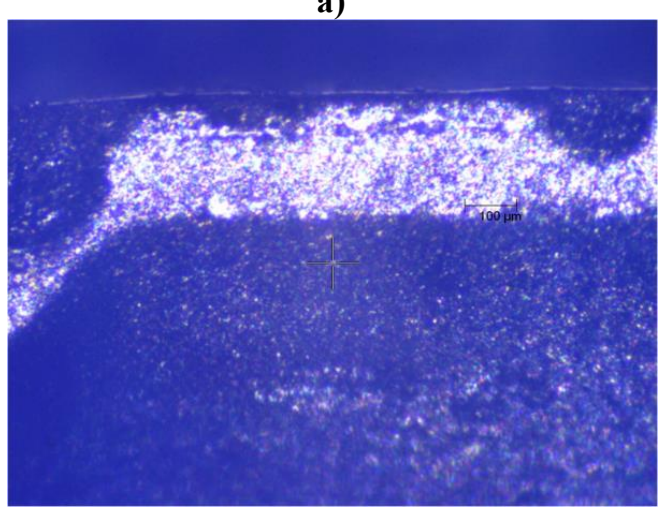

B)

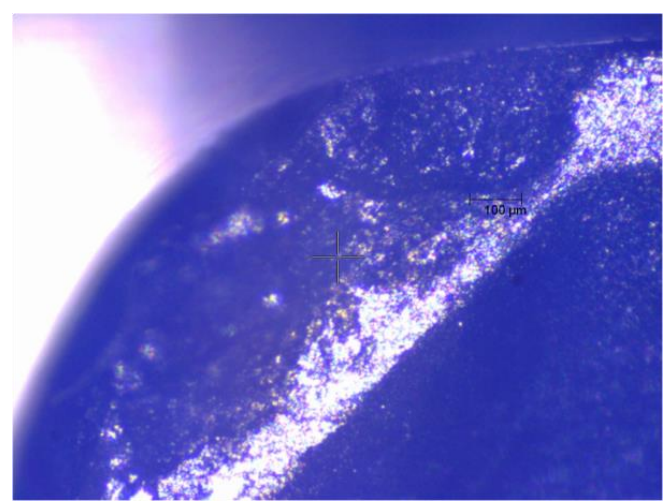

б)

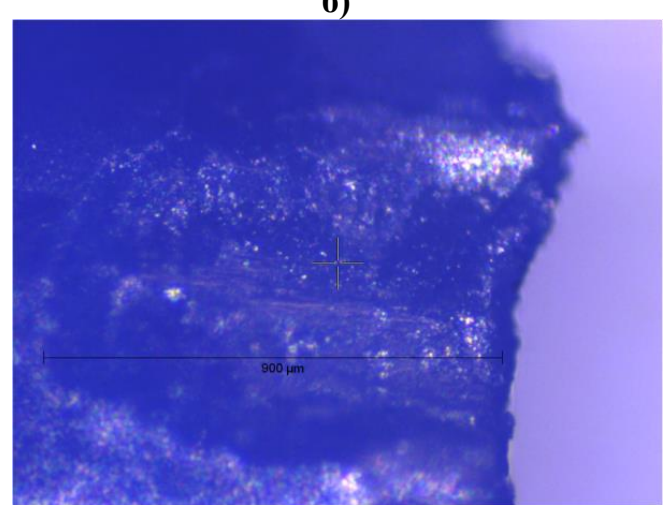

г)

Рисунок 7 - Износ поверхностей СМП после обработки на 2 режиме резания: а - главная режущая кромка, $\mathbf{0}$ - радиусная режущая кромка, в - вспомогательная режущая кромка, $\mathbf{\Gamma}$ - задняя поверхность. Увеличение в 200 раз.

ISPC Results and Perspectives,

Harrisburg, USA 
Таким образом, с увеличением частоты вращения заготовки и уменьшением скорости подачи режущего инструмента интенсивность абсолютного износа поверхностей СМП возрастает. Максимальный износ определен по задней поверхности пластины после точения на 2 режиме резания.

Характер изнашивания поверхностей и режущих кромок СМП можно представить величиной изменения диаметральных размеров ступеней обработанных деталей.

Уменьшение размеров СМП при изнашивании вызывает увеличение диаметра обработанной поверхности детали. Годность детали определяется измерением поверхностей и последующим вычислением разницы между диаметральным размером (с учетом допуска), проставленным на рабочем чертеже детали, и фактическим размером, полученным после обработки.

Были выполнены измерения микрометром диаметров ступеней обработанных деталей. В табл. 1 записаны средние значения трех измерений каждого диаметра.

Результаты измерений диаметров деталей.

Таблица 1

\begin{tabular}{|c|c|c|c|c|}
\hline \multirow{2}{*}{ Размер по чертежу, мм } & \multicolumn{2}{|c|}{$\mathbf{1}$ режим резания } & \multicolumn{2}{c|}{ р режим резания } \\
\cline { 2 - 5 } & $\mathbf{1}$ деталь & $\mathbf{2}$ деталь & $\mathbf{1}$ деталь & $\mathbf{2}$ деталь \\
\hline$\varnothing 28_{-0.15}$ & $\varnothing 27.95$ & $\varnothing 28.01$ & $\varnothing 27.98$ & $\varnothing 28.09$ \\
\hline$\varnothing 20_{-0.1}$ & $\varnothing 19.97$ & $\varnothing 20.02$ & $\varnothing 19.95$ & $\varnothing 20.08$ \\
\hline$\varnothing 11_{-0.08}$ & $\varnothing 10.99$ & $\varnothing 11.04$ & $\varnothing 10.98$ & $\varnothing 11.08$ \\
\hline
\end{tabular}

Величина допустимого износа СМП будет равна допуску на диаметр обработанной поверхности. Рассмотрим величину отклонения наиболее точного размера изготовленных деталей Ø11-0,08 мм (рис. 8).

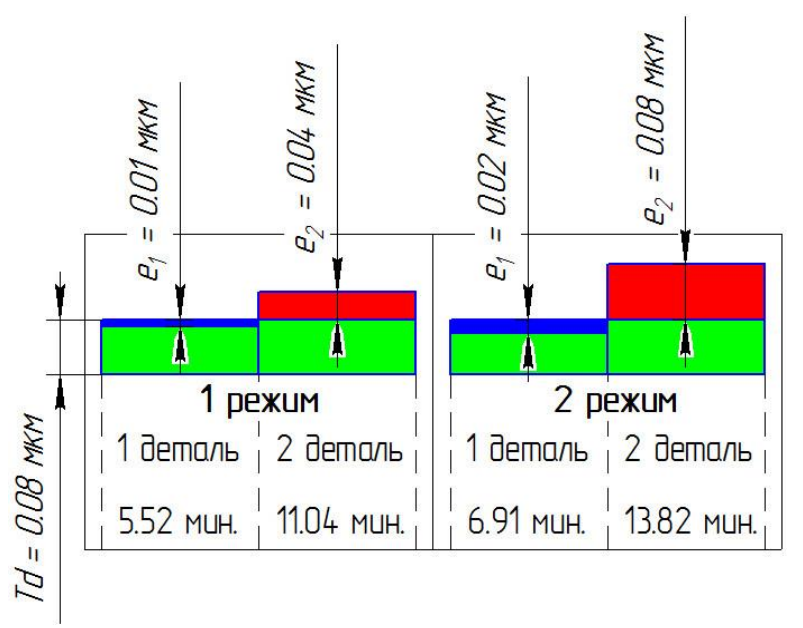

Рисунок 8 - Отклонения наружного диаметра 11-0,08 мм при износе СМП.

На схеме прямоугольник зеленого цвета соответствует допуску $(T d)$ на диаметральный размер ступени детали. После 5.52 и 6.91 минут точения на различных режимах измеренный размер диаметра находится в поле допуска (прямоугольник синего цвета). То есть величина абсолютного износа СМП не превышает предельно допустимую величину износа режущего инструмента. Полученные размеры близки к наибольшему предельному размеру $\left(e_{1}\right)$. На 11.04 и 13.82 минутах точения размер диаметра выходит за поле допуска (прямоугольник красного цвета величиной $e_{2}$ ). Это значит, что режущий инструмент значительно затупился, и требуется смена пластины или коррекция токарного инструмента на автоматизированном станке с ЧПУ.

Наиболее оптимальным из двух рассмотренных режимов резания является первый, так как производительность обработки деталей выше и износ СМП меньше в два раза. Данные СМП рекомендуется применять при черновом или получистовом точении легированных сталей. 


\begin{tabular}{l|lrl|l|ll} 
& ISRA (India) & $=\mathbf{1 . 3 4 4}$ & SIS (USA) & $=\mathbf{0 . 9 1 2}$ & ICV (Poland) & $=\mathbf{6 . 6 3 0}$ \\
Impact Factor: & ISI (Dubai, UAE) $=\mathbf{0 . 8 2 9}$ & PUHL (Russia) $=\mathbf{0 . 2 3 4}$ & PIF (India) & $=\mathbf{1 . 9 4 0}$ \\
& GIF (Australia) & $\mathbf{0 . 5 6 4}$ & ESJI (KZ) & $=\mathbf{1 . 0 4 2}$ & IBI (India) & $=\mathbf{4 . 2 6 0}$ \\
& JIF & $\mathbf{1 . 5 0 0}$ & SJIF (Morocco) & $=\mathbf{2 . 0 3 1}$ & & \\
\hline
\end{tabular}

\section{References:}

1. Gusev VG, Chemezov DA (2015) Tool wear in turning stainless-steel blanks. Russian Engineering Research, April 2015, Volume 35, Issue 4. - pp. 295-297. DOI: http://dx.doi.org/10.3103/S1068798X15040139

2. (2016) Mehanizmy iznashivaniya instrumenta. Available: http://metallrez.ru/iznos-instrumenta (Accessed: 23.07.2016).

3. (2016) Iznos rezhuschih instrumentov. Available:

http://www.info.instrumentmr.ru/rezanie/iznos rej_instrum.shtml (Accessed: 23.07.2016).

4. Lathe - operator manual (2007) Haas Automation, Inc.

5. (2016) Stal' marki 12X18H10T. Available: http://metallicheckiy-
portal.ru/marki_metallov/stk/12X18H10T (Accessed: 23.07.2016).

6. (2016) Tverdye splavy. Available: https://ru.wikipedia.org/wiki/Твёрдые сплавы (Accessed: 23.07.2016).

7. Chemezov DA, Gusev VG (2012) The functionality of the device Micro-scratch tester and the results of the measuring indentation of the machined parts. "Scientific community of students XXI century. Engineering science": materials of $\mathrm{V}$ international student extramural scientific-practical conference. Novosibirsk: Publisher "Siberian Association of Consultants". - pp. 98-102. ISBN 978-5-43790147-2.

8. Scratch \& Indentation user's manual V4 (2008) CSM Instruments SA. 